\title{
Mudanças de hábitos e saúde dos estudantes após ingresso na universidade
}

\author{
Changes in students daily habits and \\ health after they start college
}

\section{Gustavo de Barros Araújo Muniz'1 (D) Edleusa Nery Garrido² (D)}

${ }^{1}$ Autor para correspondência. Universidade do Estado da Bahia (Salvador). Bahia, Brasil. muniz6459@gmail.com 2Universidade do Estado da Bahia (Salvador). Bahia, Brasil. edleusagarrido@gmail.com

RESUMO | INTRODUÇÃO: O aumento de publicações sobre a vida do estudante do Ensino Superior demonstra o interesse crescente da comunidade científica sobre o tema. Tais estudos apontam para alterações na saúde dessa população após ingresso nesse nível de ensino. OBJETIVO: Investigar mudanças nos hábitos de vida dos estudantes que ingressam na universidade e o impacto em sua saúde física e mental. MÉTODos: Foi adotada uma pesquisa qualitativa, com o uso de entrevista semiestruturada, aplicada em oito estudantes. Os dados foram analisados mediante análise de conteúdo, o que resultou em três categorias temáticas: Mudanças nos hábitos (alimentação, sono, atividades físicas, lazer e descanso); Impactos (físicos e mentais); Determinantes envolvidos na formação de novos hábitos (socioeconômicos, acadêmicos, familiares e afetivos e outros). RESULTADOS: A alimentação foi uma das dimensões que mais apresentou alterações, assim como o sono. Quanto aos impactos físicos, foram apontadas dores musculares, cefaleias tensionais, enxaquecas e agravamento de distúrbios, como gastrite. Nos impactos mentais, registrou-se os sintomas de estresse, cansaço, desmotivação e sentimentos de solidão, impotência, isolamento, desejo de desistir e agravamento de sofrimentos psíquicos já existentes, como depressão e ansiedade. Os determinantes mais frequentes foram os sociais, que abrangem as condições socioeconômicas dos estudantes, seguido dos educacionais, que abrangem o ambiente acadêmico. CONCLUSÃO: A experiência no Ensino Superior, neste caso, na universidade, provoca mudanças nos hábitos dos estudantes após ingresso, o que resulta em impactos em sua saúde e sugere a necessidade de se repensar as formas de seu funcionamento.

PALAVRAS-CHAVE: Hábitos. Estudantes universitários. Ensino superior.
ABSTRACT | INTRODUCTION: The increasing number of publications about university students' lives reveals the growing interest that the scientific community holds in this theme. Such studies point to changes in the health of this population after entering this level of education. OBJECTIVE: The present study investigates changes in these students' daily habits after they start college and their impact on their physical and mental health. METHODS: A qualitative research was adopted, and semistructured interviews were applied to eight students. Data was verified using a content analysis technique, which resulted in three thematic categories: Habits variations (feeding, sleeping, physical activities practice, resting and leisure); life impacts (physical and mental); Determinants involved in these new habits acquisition (socioeconomic, academic, family and affective and others). RESULTS: Feeding and sleeping were dimensions that presented most transitions. The most common physical impacts were headache, migraine, muscle ache, and worsening of previous conditions such as gastritis. Regarding mental impacts, the following symptoms were registered: tiredness, stress, demotivation, loneliness, helplessness feelings, isolation, thoughts about giving up, and aggravation in previous psyche suffering as depression and anxiety. The noun determinants related to these changes were the social, which include the students' socioeconomic conditions, followed by the educational elements that comprehend the academic environment. CONCLUSION: A university's academic daily life generates multiple routine changes in their students, compromising their health. Therefore, restructuring universities organizations is needed.

KEYWORDS: Habits. College students. Higher education. 


\section{Introdução}

A preocupação com os cuidados da saúde física e mental do ser humano vem ganhando cada vez mais atenção nos últimos anos, o que é evidenciado por crescentes publicações sobre o assunto (Sousa et al., 2013; Oliveira et al., 2014; Langame et al., 2016; Mendonça et al., 2019; Oliveira et al., 2020). A necessidade desses cuidados se estende às diversas camadas da população, dentre elas a que abrange os estudantes do Ensino Superior. É trazido na literatura, por exemplo, que o ambiente acadêmico pode se tornar uma fonte de estresse para uma considerável parcela da população desse nível de ensino (Padovani et al., 2014). Além disso, mudanças nos hábitos de vida, após ingresso nesses espaços, podem trazer impactos que afetam diretamente a qualidade de vida desse grupo. Isso porque, o Ensino Superior possui uma dinâmica que vai exigir uma série de responsabilidades até então não experimentada na trajetória escolar pregressa. Portanto, mudanças nos hábitos de vida são esperadas para fazer frente às novas exigências. Resta saber: tais mudanças implicam em melhorias da qualidade de vida desse grupo populacional ou os expõem a comportamentos de risco à sua saúde?

De acordo com Langame et al. (2016) não há consenso, na comunidade científica, sobre a definição de qualidade de vida. Estes autores trazem a definição da Organização Mundial da Saúde (OMS), compreendida como "a percepção do indivíduo de sua posição na vida, no contexto da cultura e sistemas de valores nos quais vive e em relação aos seus objetivos, expectativas, padrões e preocupações" (OMS, 1995, citado por Langame et al., 2016, p. 314). A qualidade de vida pode ser explorada como uma característica que abrange diversas áreas, possuindo uma natureza, portanto, multidimensional. Também estaria relacionada a aspectos como a percepção de si que o indivíduo possui, levando em conta o seu contexto histórico-cultural, assim como suas necessidades e expectativas.

Diretamente relacionados à qualidade de vida, entende-se por hábitos aqueles comportamentos que foram aprendidos e internalizados, a ponto de se tornarem automáticos e isso se dá pela repetição (Cristo \& Günther, 2015). Nesse bojo de comportamentos habituais, alguns podem ser salutares enquanto outros podem resultar em danos à saúde. Um conjunto de hábitos determina estilos de vida das pessoas.

Por Estilos de Vida (EV), amparados pelo campo da epidemiologia, Madeira, Filgueira, Bosi e Nogueira (2018), colocam que estes são vistos como uma gama de comportamentos do âmbito individual, que podem propiciar saúde, esta vista sob o prisma de um fenômeno estritamente biológico. Seguem as autoras afirmando que o embasamento teórico pautado na Promoção da Saúde (PS) é ampliado, uma vez que empreende esforços em incorporar o conceito da determinação social ao discutir as relações entre EV e saúde.

Quando o foco do estudo se volta à saúde do estudante universitário, é de suma importância trazer a temática dos determinantes sociais da saúde que estão envolvidos nesse processo. Segundo Batistella (2007), os determinantes podem ser explicados como as condições regidas por diversos aspectos gerais de uma sociedade, como a economia, a política, a cultura e o ambiente em que os indivíduos estão inseridos e de que forma essas condições se relacionam com os hábitos e funcionamento dos mesmos em seu meio. Portanto, estão sendo referidas características como moradia, saneamento básico, educação, racismo, sexismo, serviços de saúde oferecidos, transporte, trabalho, dentre outras.

Tendo em vista a importância dos diversos ambientes no qual os sujeitos estão inseridos, é mister refletir sobre quais determinantes sociais da saúde podem estar vinculados ao estudante do Ensino Superior e de que forma estes influenciam para a mudança de seus hábitos, incluindo aqueles que o levam a comportamentos de risco. Vale destacar, também, que estratégias de coping ${ }^{1}$, ou enfrentamento, como trazido no estudo de Oliveira et al. (2014), estão relacionadas com a manutenção desses hábitos e adaptação do estudante ao ambiente acadêmico e estas implicam, fundamentalmente, com os determinantes, assim como por comportamentos de risco.

\footnotetext{
1 Por coping, os autores afirmam se tratar de uma gama de estratégias tanto cognitivas quanto comportamentais que são empregadas pelos sujeitos para lidar com o excesso de demandas resultantes de situações estressoras (Lazarus \& Folkman, 1984, citado por Oliveira et al., 2014).
} 
A OMS define esses comportamentos como causadores de consequências adversas para o indivíduo ou que aumentem a probabilidade de estas ocorrerem. Em complemento, afirma que, dentre os comportamentos mais registrados, estão o consumo de bebidas alcoólicas, o hábito de fumar, uma má alimentação, assim como a falta de atividades físicas (WHO, 2014). Sousa, et al. (2013), revelam que diversos estudos demonstram como os estudantes universitários estão em um grupo considerado predisposto a esses comportamentos de risco citados pela OMS. Em suma, o consumo de bebidas alcoólicas (Oliveira et al., 2020), a má alimentação (Mendonça et al., 2019) ou o baixo nível de atividades físicas (Couto et al., 2019) entre estudantes do Ensino Superior são exemplos trazidos na literatura.

Outro aspecto importante, que se apresenta crescente nos resultados de investigações, diz respeito aos impactos da vida acadêmica na saúde dos estudantes, a exemplo de estudos que discutem: sofrimento mental (Padovani et al., 2014; Andrade et al., 2016); baixa qualidade do sono (Araújo et al., 2016; Salvi, Mendes \& Martino, 2020); níveis de estresse elevados (Moretti \& Hübner, 2017; Silva et al., 2020); dores no corpo, dermatite, enxaquecas e crises de choro (Bonifácio et al. 2011), assim como ideação suicida (Pereira \& Cardoso, 2015).

A exposição desse contexto, que a literatura apresenta, aponta para a necessidade de ampliação do conhecimento acerca dos hábitos de vida que os estudantes desenvolvem ao ingressar no Ensino Superior, assim como a identificação dos determinantes que cooperam com essas mudanças. A preocupação que se revela é quanto às implicações dessas mudanças na saúde dessa população. Sendo assim, o objetivo deste artigo é o de refletir sobre os impactos dos hábitos cotidianos na saúde dos estudantes, após ingresso no Ensino Superior, e levantar os determinantes envolvidos na formação desses novos hábitos.

\section{Métodos}

Este artigo discute um recorte do projeto de pesquisa intitulado "Trajetórias estudantis e questões emergentes na experiência universitária". O projeto foi submetido ao Comitê de Ética em Pesquisa, cujo parecer de aprovação (CAAE 82563418.1.0000.0057) está em conformidade com a Resolução n 510/2016 do Conselho Nacional de Saúde (2016). Para garantir o anonimato dos participantes, foram adotados nomes fictícios.

O estudo é de natureza qualitativa, com graduandos de uma universidade pública do estado da Bahia, maiores de 18 anos e que aceitaram participar do estudo de forma voluntária. A partir do critério de conveniência, neste caso a aproximação dos pesquisadores com um dos departamentos da instituição e, a fim de contemplar todos os cursos nele existentes, a amostra consistiu em dois estudantes de cada um dos cursos de Ciências Sociais, Filosofia, Pedagogia e Psicologia. A abordagem inicial com esses sujeitos se deu em um ambiente compartilhado por estudantes de todos os cursos como espaço de socialização. $\mathrm{Na}$ ocasião, um dos autores do presente estudo se reuniu com os presentes naquele ambiente e explicou sobre os propósitos da pesquisa ao tempo em que convidou voluntários, resultando em oito participantes.

Um roteiro para a entrevista semiestruturada foi elaborado, composto por oito itens, direcionados a explorar mudanças nos hábitos dos estudantes, assim como possíveis impactos na saúde e determinantes envolvidos. O roteiro foi ajustado após aplicação do estudo piloto com dois estudantes da instituição, para fins de atender com mais especificidade aos objetivos propostos, neste caso foi necessário apenas o reordenamento das perguntas. Como complemento, foi construído um formulário para a caracterização dos perfis discentes. Para a produção dos dados, inicialmente foi apresentado um Termo de Consentimento Livre e Esclarecido (TCLE) a cada participante informando sobre a finalidade da pesquisa e a garantia do anonimato na divulgação dos resultados; após assinado, seguiu-se com a entrevista.

Por fim, os dados produzidos foram analisados mediante a Análise de Conteúdo, que, segundo Bardin (2009), consiste em um instrumental metodológico com uma vasta área de aplicação, podendo ser definido como uma estratégia de leitura dos conteúdos manifestos, das figuras de linguagem empregadas, assim como o que se revela por trás do discurso apresentado e suas formas simbólicas. A partir desse material, o processo de categorização foi realizado a posteriori, sendo a elaboração das categorias, portanto, construída após a análise sistemática do material. Em suma, as categorias foram construídas após a leitura, 
por meio da identificação de padrões presentes entre as unidades de análise encontradas (recortes contextuais), visando responder aos objetivos propostos, a saber: as mudanças de hábitos decorrentes do ingresso na universidade; os impactos produzidos, e os determinantes envolvidos neste processo. Optou-se pela análise temática que, segundo a autora, se ocupa dos temas recorrentes que são extraídos da totalidade dos discursos. Os agrupamentos de unidades semelhantes deram origem a categorias próprias.

A seguir, estão descritas as categorias temáticas e suas subsequentes subcategorias:

Categoria I (Mudança nos hábitos) - Abrange quatro subcategorias que apontam onde ocorreram as principais mudanças nos hábitos dos estudantes universitários após o ingresso na universidade: I.1 (Alimentação); I.2 (Sono); I.3 (Atividades físicas) e 1.4 (Lazer e descanso).

Categoria II (Impactos) - Abrange duas subcategorias sobre como os estudantes sentiram o efeito intenso das mudanças dos hábitos, após o ingresso na universidade: II.1 (Físicos) e II.2 (Mentais).

Categoria III (Determinantes envolvidos na formação de novos hábitos) - Abrange quatro subcategorias, que são relativas aos principais fatores que possuem influência na construção e consolidação dos novos hábitos após o ingresso na universidade: III.1 (Socioeconômicos); III.2 (Acadêmicos); III.3 (Familiares e afetivos) e III.4 (Outros).

\section{Resultados e discussão}

Dos oito estudantes entrevistados, metade eram mulheres. Sobre o semestre em vigor, quatro relataram estar no $6^{\circ}$ semestre e quatro no $8^{\circ}$ semestre. Quanto às características étnico-raciais, três estudantes se identificaram como pretos, três como pardos e dois como brancos. A faixa etária variou dos 20 aos 44 anos. Sobre o grau de escolaridade dos pais, três estudantes relataram que os pais tinham ensino médio completo, um com ao menos um dos pais com ensino médio completo, dois com ao menos um dos pais com Ensino Superior completo e um com os pais pós-graduados. Apenas um relatou ter ambos os pais com fundamental incompleto.
Enquanto quatro afirmaram estar em atividade de estágio, um afirmou receber bolsa e outro proferiu que trabalha e recebe bolsa. Apenas dois estudantes relataram não estar trabalhando, estagiando ou recebendo bolsa. Isso revela como a maioria dos estudantes da amostra está engajada em outras atividades além da sala de aula, exigindo, portanto, uma organização mais elaborada do tempo de cada um e que pode refletir nos hábitos de vida.

Na categoria I, Mudanças nos Hábitos, diversas unidades de análise puderam ser reunidas, ilustrando a percepção dos estudantes sobre as múltiplas alterações em seus hábitos após ingresso na universidade. Relatos, como o do trecho a seguir, expõem essas mudanças:

Alimentação foi o principal; depois que eu entrei na universidade, meus hábitos alimentares ficaram bem ruins, principalmente por causa do tempo e da conveniência de não ter que fazer comida sempre [...] eu já passei muitas vezes por isso, algo de já ter ouvido muitos colegas falarem, que não estão tendo tempo de almoçar, come só quando chega em casa, um bom prato, uma refeição grande e geralmente, uma só. [...] Algumas vezes isso já aconteceu, mas eu escolhi... parei pra ver "esse não sou eu, eu não fui criado assim, eu sei me alimentar" (Freud, de Filosofia).

Depoimentos como o apresentado acima compreendem a subcategoria Alimentação (I.1), que expressa o quanto os hábitos alimentares dos estudantes são modificados após ingresso na universidade. Nesse conjunto, puderam ser observadas algumas das principais mudanças constatadas nesse âmbito, reconhecidas pelo estudante. Em outro relato:

A minha principal mudança na alimentação foi que eu passei a pular o café da manhã. [...] Eu tinha um número de refeições maiores antes de ingressar na universidade, depois que eu entrei na universidade meu ritmo de alimentação mudou e eu passei a me alimentar com menos frequência. Fazer refeições maiores, só que menos refeições

(Skinner, de Psicologia).

Quase todos os estudantes pontuaram mudanças na alimentação, ao menos em algum nível. As principais foram relacionadas à ausência de uma regularidade para se alimentar, no número de refeições diárias e nos tipos de alimentos consumidos. Alguns estudantes também mencionaram estar ingerindo 
diariamente mais café e chá verde, bebidas essas com teor expressivo de cafeína. Esses resultados são convergentes com os achados de Mendonça et al. (2019), em seu estudo sobre a percepção da saúde e qualidade de vida entre estudantes de medicina. Nele, também foi registrado que uma alimentação irregular, provocada principalmente pelo excesso de atividades curriculares, afeta o gerenciamento do tempo destinado à alimentação, assim como aumento na escolha de alimentos com características pouco saudáveis.

Depoimentos como o do trecho a seguir, expõem essas mudanças:

Não é nada saudável (risos), e também não tenho horários certos pra me alimentar, é de acordo com o intervalo de tempo que vou ter entre uma coisa e outra.

[...] antes da universidade eu já... eu sempre tive uma alimentação assim... mais saudável, tinha horários pra me alimentar. [...] a alimentação era mais equilibrada, mais saudável, tinha os horários certinhos. Mas eu acho que após a entrada na universidade, muita coisa mudou [...] (Nise, de Pedagogia).

Essas alterações foram diretamente relacionadas à entrada na universidade, devido à dificuldade em conciliar o tempo apropriado para cada refeição, a seleção do tipo de alimento, assim como o tempo para preparar a própria comida. Pela possibilidade de trazer consequências prejudiciais à saúde, vale destacar que uma má alimentação pode ser considerada como um comportamento de risco (WHO, 2014).

Na subcategoria Sono (I.2), foram encontradas mudanças após a entrada dos estudantes na universidade, desde o sono agitado até o desenvolvimento de distúrbios do sono, como a insônia. Isso pode ser percebido na fala a seguir:

Sono é um fator bem ruim. Eu tenho insônia. Têm dias que eu durmo tranquilamente e outros dias que não, que eu fico acordado de madrugada, praticamente o dia todo. Sono é algo que me incomoda bastante. [...] e depois da [XXX] a questão da insônia surgiu em... por exemplo, ontem foi quarta, não? De terça pra quarta eu não dormi. Praticamente de segunda pra terça também não. Então todos esses dias eu tô ligado. (Jung, de Ciências Sociais)

Alguns estudantes afirmaram acordar diversas vezes numa única noite de sono, assim como ter sono agitado, o que costuma não ser revigorante.
A demora para adormecer, pesadelos, sonolência ao longo do dia e distúrbios como a insônia também foram pontuados. Isso pode ser exemplificado em:

Eu durmo assim, o dia todo, várias vezes. Se eu encostar num lugar, durmo. É ruim, porque é um sono que não é contínuo. Acho que umas quatro horas... aí interrompe, depois mais duas... umas seis horas. [...] sempre tive um sono bem tranquilo. Só que agora eu acordo mais vezes, fico pensando, não consigo parar de pensar... é estranho (risos), não consigo parar de pensar. [...] Aí eu durmo, mas como eu falei a você, não é um sono contínuo, sempre interrompido por esses pensamentos daquilo que eu poderia ter feito.

(Virginia, de Filosofia)

A privação do sono leva o indivíduo a alterações na cognição e no comportamento, assim como variações hormonais e neuroquímicas (Tufik et al., 2015). As mudanças na qualidade do sono, por sua vez, são responsáveis pelo prejuízo significativo na vida dos indivíduos (Araújo et al., 2016; Salvi et al., 2020). À medida que as atividades ao longo do semestre vão se intensificando, a qualidade do sono vai reduzindo gradualmente, notadamente devido ao estresse e à ansiedade que predominam nesse período.

Quanto às mudanças nas práticas de Atividades físicas (1.3), a dinâmica da universidade foi mencionada como principal causadora dessas alterações, incluindo várias atividades que foram interrompidas. A alegação se reporta à necessidade de dedicação à universidade ou por demandas extracurriculares. Isso remete a uma impossibilidade de conciliação, pois se apresenta como um dilema em que a atividade física perde seu lugar de prioridade diante dos compromissos com a formação. Isso pode ser observado através do trecho:

Antes do estágio, antes de começar os estágios, eu comecei a fazer caminhada. Eu daqui da [XXX] eu ia pra casa andando [...], mas com o estágio e a residência, $e$ muitas outras coisas assim, eu não tive como... como fazer atividade física, porque os horários não dão pra mim. (Nise, de Pedagogia)

Antes eu praticava, fazia caminhada. Hoje eu não tenho mais como. [...] Isso foi antes da universidade, porque eu caminhava sempre pela manhã. E agora como eu tô fazendo, pegando disciplina de manhã e à noite, aí não tem como. E o trabalho de tarde, aí fica mesmo muito... muito complicado (Von Franz, de Pedagogia). 
Como pode ser visto, os compromissos acadêmicos limitam o tempo dos estudantes levando-os a desistir da atividade física ao longo do curso. Um estudo conduzido por Couto et al. (2019), no Distrito Federal, revelou que o nível de atividade física dos universitários que frequentavam aulas no turno noturno era inferior ao daqueles que frequentavam aulas durante o dia. Convém ressaltar que $65,4 \%$ dos estudantes que frequentavam as aulas à noite trabalhavam e estudavam, enquanto no período diurno esse percentual era de $43,9 \%$, o que sugere menor tempo livre do primeiro grupo para a realização de atividade física. Além disso, os autores verificaram que $55,4 \%$ de toda a amostra alegou a falta de tempo à prática dessas atividades como principal justificativa.

Vale destacar que a ausência de atividades físicas na vida cotidiana também é considerada como um comportamento de risco, capaz de elevar a incidência de doenças cardiovasculares, diabetes, assim como uma gama de distúrbios, a exemplo da obesidade (WHO, 2014).

A subcategoria Lazer e descanso (I.4) representa as principais alterações relacionadas a esses hábitos. Foi observado que a maioria dos entrevistados não dissociou o lazer do descanso em seus relatos, ou seja, foram trazidos como fatores interconectados, como pode ser visto a seguir:

Eu senti uma mudança, porque a universidade, ela é mais extenuante do que o colégio, então... eu precisei passar a despender mais tempo nos estudos. Se no colégio eu precisava estudar uma, duas horas por dia, na faculdade eu precisei dobrar, triplicar pra poder conseguir dar conta de todas as demandas, então meu tempo de lazer diminuiu. [...] Então as demandas da universidade aumentaram a quantidade de tempo que eu tinha que me dedicar a ela. Basicamente. Reduziu consideravelmente meu descanso e lazer [...].

(Skinner, de Psicologia)

Em relação à leitura, eu passei a ler mais porque eu sempre consigo fazer um conciliamento interessante entre a literatura e a filosofia, são áreas que dialogam, mas em relação ao lazer sim, meus hábitos de lazer mudaram muito, muito depois que eu entrei na universidade. Eu passei a achar muito exaustivo me divertir como eu me divertia na época do colégio, principalmente porque eu estudo de noite (Freud, de Filosofia).
Foram registradas mudanças consideráveis pela maioria dos entrevistados, principalmente no que se refere à diminuição do tempo dedicado para as atividades que poderiam proporcionar relaxamento das obrigações do cotidiano. Como observado por Bonifácio et al. (2011), os hábitos de lazer e descanso são postos de lado e há uma priorização exclusiva da produção acadêmica irrefreável.

Justamente o que seriam hábitos que agiriam de forma a prevenir e agir contra o estresse, conforme afirmam Moretti e Hübner (2017), são renunciados em prol de uma manutenção, fatigante, das demandas da universidade, o que pode acarretar sofrimento e até mesmo adoecimento. Não houve alterações significativas no tipo de atividades realizadas, com exceção apenas da leitura que, em diversos casos, foi mencionado o aumento dessa atividade, se comparado com o período anterior ao ingresso na universidade.

A categoria II, Impactos, reúne as unidades que mais expressam as percepções sobre os principais efeitos sentidos pelos estudantes após a entrada na universidade. Um exemplo de relato que se encaixa na subcategoria de impactos Físicos (II.1) é:

[...] pode ter acontecido assim, algum... algum tipo de situação... por exemplo, enjoo em decorrência do estresse. [...] eu acredito que em algum momento eu possa ter tido um problema de saúde, dor de cabeça, em decorrência do estresse promovido pela universidade. Enjoo, dor de cabeça, como eu falei, pressão baixar em decorrência do nível de adrenalina. Quando eu fico muito, muito nervoso, desesperado, a minha pressão cai e eu começo a suar muito, as vistas escurecem. Isso já aconteceu aqui nesse ambiente, entendeu? Quando você não tá bem aqui, isso reflete na sua saúde, você diminui... tem uma diminuição no apetite e você não fica em paz mental. Isso muitas vezes acaba me provocando tremedeira... que às vezes

a pressão baixa, a respiração fica ofegante, então é basicamente isso que eu sinto [...]. (Perls, de Ciências Sociais.)

Todos os entrevistados mencionaram algum impacto no organismo, após o ingresso na universidade. A queixa de dores musculares, principalmente nos ombros, pescoço e nas costas, pode estar relacionada ao acúmulo de tensão devido ao constante estresse. Os estudantes também trouxeram a perda de apetite e, em consequência, perda de peso, azia, queda de 
pressão arterial, náuseas, tremedeira, parestesia no abdômen, palpitações e sudorese. Foram apontadas, ainda, situações mais críticas como o agravamento de alguns distúrbios, como a gastrite, que foi relatada por um dos estudantes, atingindo seu pico durante o curso. A fala a seguir traz um exemplo de agravamento de uma condição pré-existente:

Tinha problemas de saúde que eles se agravaram com a entrada na universidade. Por exemplo, eu descobri a gastrite pouco antes de entrar na universidade $e$ ela atingiu seu pico, seu auge mesmo quando eu tava estudando aqui. Aí foi o período que ela passou em crise, que eu sentia muita dor (Skinner, de Psicologia).

O aparecimento de sintomas psicossomáticos e sua relação com as circunstâncias vivenciadas durante o curso foi trazido por Mendonça et al. (2019), que trouxeram resultados que relacionam o estresse, a privação do sono e os eventos da vida diária com o surgimento de uma gama de sintomas como cefaleia, dores nas costas, ansiedade, arritmia e insônia, além de uma série de distúrbios gastrointestinais, incluindo também a presença de gastrite. Resultado semeIhante também foi visto por Bonifácio et al. (2011), por meio de uma investigação sobre eventos estressores em estudantes de psicologia, cujo resultado evidenciou que a sobrecarga de atividades da universidade está atrelada ao surgimento de sinais de estresse em âmbito físico e psicológico.

Na subcategoria de impactos Mentais (II.2), também há exemplos de estudantes com sinais de sofrimento psíquico em decorrência de estresse, o que gera uma gama de sintomas, tais como: ansiedade, fadiga mental, crises de choro, desmotivação, irritabilidade, sentimentos de inferioridade e solidão e, em alguns casos, o agravamento de transtornos mentais, como o transtorno de ansiedade generalizada e a depressão. Isso fica explícito nos trechos a seguir:

Geralmente eu já fiquei assim em níveis tão estressantes de querer abandonar tudo. Eu já abandonei disciplinas por questões mesmo de não dar conta de fazer [...]. Fico desmotivada, abandono as coisas, não faço, às vezes fico chorando [...] quando você paralisa e não consegue dar continuidade a nada

e aí você não consegue compreender nem às vezes o que você tá fazendo [...]. Eu geralmente me isolo, quando eu passo por alguma coisa assim que não sei lidar [...]. Mas o problema de me isolar é que eu fico me sentindo mal por estar ali sozinha, sabe? Então é algo meio complicado. Ao mesmo tempo em que eu quero ficar só, eu fico mal por estar só, quero ter alguém pra me apoiar, estar ali. (Nise, de Pedagogia)

Geralmente vem acoplada com uma ansiedade e me sinto mais desconcentrada, com menos foco. Sinto mais dificuldade em me concentrar pra estudar, por exemplo. [...] Me sinto mais irritada. Me considerava uma pessoa paciente, e acho que nesse momento eu fico mais à flor da pele. (Klein, de Psicologia)

Sintomas de estresse contínuo e cansaço foram detectados em todos os estudantes. Alguns mencionaram sentirem-se desmotivados, assim como o aparecimento de sentimentos de solidão, de impotência, sensação de isolamento e desejo de desistir. Alterações no humor também foram pontuadas, como aumento da irritabilidade, bem como crises de choro. Em outro caso, cansaço extremo e esgotamento mental também foram relatados.

Os achados elencados no presente estudo convergem com a visão de Padovani et al. (2014) sobre a questão da vulnerabilidade do estudante universitário frente à carga excessiva e adoecedora das exigências acadêmicas. Alguns estudantes, de acordo com os autores, também assumiram já terem sido diagnosticados com transtornos de ansiedade e depressão, tomando remédios controlados, e frisaram como os sintomas se agravaram após a entrada na universidade.

Moretti e Hübner (2017) verificaram a relação entre a rotina acadêmica extenuante e os níveis de estresse em estudantes da graduação. No estudo, a presença da ansiedade foi significativa, assim como uma prevalência elevada de estados de exaustão entre os estudantes. Já Silva, Pereira e Moura (2020) pesquisaram a relação entre qualidade de vida e transtornos mentais menores e encontraram que os estudantes revelaram elevada frequência de sentimentos como mau humor, ansiedade, desespero e depressão, além de cansaço e exaustão, assim como qualidade do sono precária e pouco tempo para o lazer.

A categoria III, Determinantes envolvidos na formação de novos hábitos, abrange as unidades que representam os padrões de fatores que puderam ser observados pelos estudantes como importantes para a formação dos novos hábitos. Nos relatos trazidos pelos entrevistados do presente estudo, percebe-se que há determinantes socioeconômicos, acadêmicos, familiares, afetivos e outros que influenciam diretamente na formação e consolidação de novos hábitos, 
os quais, em sua maioria, dificultam ou trazem alguns prejuízos no percurso acadêmico traçado pelo estudante universitário.

Na subcategoria dos determinantes Socioeconômicos (III.1) foi observado como esses fatores possuem uma intensa influência na vivência acadêmica do estudante universitário, como é possível verificar no próximo recorte de fala:

Ter que dar conta de todas as disciplinas, de preparar as coisas para poder trazer pra vender aqui, porque é como eu me mantenho. Basicamente isso, as preocupações do dia a dia. De contas que tão chegando, aluguel, luz, água, essas coisas comuns do dia a dia. E são bem estressantes. (Von Franz, de Pedagogia.)

A questão financeira foi pontuada, como a necessidade de uma renda suficiente para a alimentação, transporte, cópias de material da universidade, dentre outros gastos. Estudantes que se preocupam em organizar e pagar despesas domésticas, como conta de água, energia e aluguel, reconheceram esses compromissos como estressantes. O deslocamento de casa até a universidade, estágio ou local de trabalho, também foi mencionado como desgastante para os estudantes. Relatos como a mudança no hábito de passar mais tempo fora de casa também foi recorrente. Isso pode ser visto em:

\section{[...] um tempo maior fora de casa. Porque normalmente} eu vou pra $[X X X]$ de manhã e tenho o costume de almoçar aqui mesmo, ficar a tarde inteira estudando ou adiantando algum trabalho, entendeu? E só vou embora às dezoito horas. E tenho muito o costume de fazer isso. Então levando em conta que as minhas aulas são de segunda a sexta, então é mais tempo que eu passo fora de casa (Perls, de Ciências Sociais)

Todos esses determinantes socioeconômicos mencionados consoam com o que foi encontrado na literatura, sendo capazes de influenciar na formação dos novos hábitos e na própria formação do estudante como um todo. Isso é compatível com o conteúdo conceitual de determinantes sociais da saúde apontados por Batistella (2007), expondo uma relação complexa entre os indivíduos e seu ambiente para além de uma relação simplista de causa e efeito. No caso deste estudo, seria reducionista assumir que os determinantes socioeconômicos apontados causaram a mudança nos hábitos, mas, é possível inferir que parte de uma complexa rede de fatores que, quando associados, influenciaram nas mudanças, conforme as necessidades exigidas. Oliveira et al. (2014), a partir de uma revisão sistemática da literatura, apontam para a necessidade de mais estudos voltados à compreensão das estratégias de coping no contexto acadêmico nacional, atentando-se para as distintas classes econômicas dos estudantes.

A subcategoria dos determinantes Acadêmicos (III.2) envolve unidades que representam aspectos relativos à própria universidade que dificultam a experiência acadêmica e comprometem a formação do estudante. Isso pode ser visto no trecho:

Que eu não deveria estar estressada, já que a universidade é um local que eu escolhi e que essa rotina de estudar do estudante do noturno faz parte daquilo que eu escolhi. Então eu deveria estar adequada a isso, já que já tem, o quê... quatro anos de universidade praticamente. [...] Eu não consigo parar de pensar nisso [...] eu acho que eu poderia estar produzindo mais se eu não me importasse tanto ou se eu tivesse me adequado melhor. (Virgínia, de Filosofia)

Sobrecarga de leitura, necessidade de se adequar de acordo com as exigências acadêmicas, burocracia constante, problemas de comunicação entre docentes e discentes, a infraestrutura da universidade, dentre outros, foram fatores observados como influenciadores na formação de novos hábitos. Isso também é visto em:

Na época da faculdade, eu costumo sentir isso (estresse e cansaço) quase todos os dias da semana assim, pelas demandas acadêmicas mesmo. E dá sempre essa sensação que não vai dar pra cumprir tudo há tempo e que, enfim, você é exigido mais do que você pode dar (Klein, de Psicologia).

Os determinantes acadêmicos dizem respeito à constante sobrecarga de atividades, tanto curriculares quanto extracurriculares, como a participação em trabalhos voluntários, projetos e estágios. A carga horária e a quantidade extenuante de disciplinas foram abordadas, sendo determinantes importantes para a formação de novos hábitos, justamente porque exigiam uma maior gestão do tempo para corresponder às demandas, muitas vezes comprometendo os antigos hábitos e favorecendo o desenvolvimento de novos que se adequassem à imposição desse ritmo. Foi observado, por exemplo, no relato de um entrevistado, que este se ausentava de algumas aulas, devido à exaustão mental, o que concorda com o que foi visto 
por Moretti e Hübner (2017), no que tange a constante sobrecarga acadêmica.

Também foi destacado como a universidade ainda não está preparada para receber a diversidade de perfis existentes na população estudantil, com sua gama de demandas, tal como aqueles que necessitam de suporte e acompanhamento, devido à presença de transtornos que envolvem ansiedade acentuada ou depressão, impondo o mesmo ritmo de cobrança extenuante pelas exigências acadêmicas, ao invés de favorecer um olhar mais atento para as necessidades individuais de cada estudante. Esse dado remete ao estudo de Selau et al., (2017) sobre a importância de a universidade repensar as estratégias sobre a adaptação, levando em conta a diversidade de perfis presentes nos estudantes de ensino superior.

A subcategoria dos determinantes Familiares e afetivos (III.3) reuniu apenas duas unidades de registro, embora durante os relatos houvesse frequentes referências a amigos ou familiares. Isso se deu, porque somente foram consideradas as unidades que reportassem diretamente esses determinantes como importantes para a formação de novos hábitos:

Geralmente eu busco apoio em outras pessoas, amigos, familiares, minha namorada principalmente... aí são pessoas que, às vezes, dão aquele ânimo de "continue", às vezes me dão estratégias de como fazer... "você pode fazer isso dessa maneira, modificar esse hábito, trocar isso por isso." (Skinner, de Psicologia)

Os determinantes familiares e afetivos influenciaram na formação de hábitos, como visto no relato acima, apontando que, por meio da interação entre familiares e outros vínculos afetivos, há uma troca de informações sobre as situações experienciadas, e como esse processo acaba levando à formulação de novos hábitos e estratégias para lidar melhor com demandas acadêmicas. Além disso, o suporte e apoio afetivo foram percebidos como importantes aliados frente ao sofrimento psíquico vivenciado durante o curso. Oliveira et al. (2014) mostram como a presença ou não da família, assim como da rede de amizades, pode estar relacionada à adaptação acadêmica. Esse apoio familiar e afetivo, em alguns dos estudos revisados pelas autoras, favorece o desenvolvimento de estratégias de enfrentamento para a adaptação ao ambiente.
A subcategoria Outros (III.4) reuniu três unidades de registro em que apareceram determinantes mais isolados, embora não menos significativos. Foram apontados tanto comportamentos de risco, como beber e fumar, quanto um determinante filosófico, capazes de influenciarem na formação de novos hábitos. Isso pode ser expresso em:

[...] eu acho que depois que eu entrei na universidade, isso é inclusive uma constatação empírica, a quantidade de bebidas alcoólicas que eu passei a consumir na faculdade junto com os alunos é pungente, sem dúvida. O hábito de usar como uma tentativa de escapar da vigência do ambiente universitário é inegável. E eu também me encaixei nesse nicho como, às vezes uma saída agradável, não que isso me consuma muito, mas às vezes eu falo "tudo que eu quero agora é ir pro bar e conversar com meus amigos." (Freud, de Filosofia)

O relato anterior corresponde a um dos comportamentos de risco relacionados ao uso de substâncias psicoativas, conforme menciona a OMS (WHO, 2014). Além disso, a adoção de filosofias de vida influenciou na aquisição de novos hábitos. O uso das substâncias psicoativas foi relacionado ao escapismo acadêmico das demandas extenuantes e foi registrado com um aumento considerável após o ingresso na universidade. Já a mudança de hábitos devido à adoção de uma nova filosofia de vida não foi encontrada na revisão de literatura, sendo, portanto, um aspecto novo a ser explorado em outros estudos.

No geral, constatou-se que o ingresso no Ensino Superior trouxe impactos expressivos na saúde de todos os entrevistados, sendo que alguns hábitos foram alterados em sua rotina de forma substancial. Os determinantes envolvidos nessas mudanças dizem respeito a outros aspectos da vida estudantil, mas também aqueles relativos à vida acadêmica. Isso porque o ingresso do estudante no Ensino Superior é um período de mudanças profundas, pois a vida acadêmica exige uma dinâmica cotidiana para fazer frente às diversas tarefas e compromissos a serem cumpridos.

Dessa forma, a aquisição de novos hábitos gera impactos que afetam, de forma expressiva, a vida do estudante, tanto no aspecto pessoal quanto no acadêmico. Os resultados desta investigação expõem as dimensões as quais as mudanças nos hábitos dos 
estudantes entrevistados foram mais intensas, os impactos decorrentes, assim como os principais determinantes na formação desses novos hábitos.

Diversas sugestões sobre o cuidado com a saúde física e mental, por parte da instituição de ensino, foram oferecidas pelos entrevistados, a exemplo de incentivo a mais programas de práticas de atividades físicas destinadas aos estudantes, professores e técnicos; formação de campeonatos e ligas atléticas; um olhar mais compreensivo por parte dos professores; mais flexibilidade para alterações na grade curricular e uma menor burocratização para resolver pendências; cursos de oratória e de técnicas de aprendizagem. Ademais, foi enfatizada a necessidade de ampliação dos serviços de acompanhamento psicológico destinado à população discente.

\section{Considerações Finais}

Os resultados da presente investigação permitem inferir que a universidade adota um modelo de funcionamento do processo formativo que impacta na saúde física e mental de seus estudantes, resultado que converge com o de outros estudos aqui mencionados. Trata-se de uma estrutura curricular que, com suas exigências, sobrecarrega o tempo dos estudantes na execução de tarefas, afetando a qualidade do sono, da alimentação e outros aspectos, comprometendo sua qualidade de vida.

Considerando a mudança nos hábitos de vida dos estudantes, nem sempre saudáveis, após o ingresso na universidade, é importante refletir sobre estratégias institucionais que levem em conta esses aspectos, de modo a criar condições para o acolhimento da população estudantil em suas demandas e necessidades. Além disso, uma estrutura curricular mais flexível, que permita ao estudante conciliar as obrigações acadêmicas com aquelas de descanso e lazer certamente contribuiriam para o desenvolvimento de hábitos mais salutares.

É preciso deixar claro, também, que a aquisição de novos hábitos, após o ingresso na universidade, não se restringe à experiência estudantil, mas certamente a vivência acadêmica é um forte determinante para tais mudanças. Dessa forma, defende-se a importância de políticas institucionais voltadas para assegurar que a vida acadêmica possa estimular hábitos salutares.

Embora os achados aqui elencados apresentem convergências com resultados de outras pesquisas, o presente estudo não teve a pretensão de fazer generalizações, considerando o tamanho reduzido da amostra, o que sugere o aprofundamento desta realidade nos diversos contextos do Ensino Superior.

\section{Contribuições dos autores}

Muniz, G. B. A. foi responsável pela revisão de literatura, construção dos instrumentos e coleta dos dados, transcrição das entrevistas, análise de conteúdo dos dados, redação do artigo científico. Garrido, E. N. foi responsável pela revisão de literatura, análise dos dados e redação do artigo científico.

\section{Conflitos de interesses}

Nenhum conflito financeiro, legal ou político envolvendo terceiros (governo, empresas e fundações privadas, etc.) foi declarado para nenhum aspecto do trabalho submetido (incluindo, mas não se limitando a subvenções e financiamentos, participação em conselho consultivo, desenho de estudo, preparação de manuscrito, análise estatística, etc.).

\section{Referências}

Andrade, A. S., Tiraboschi, G. A., Antunes, N. A., Viana, P. V. B. A., Zanoto, P. A., \& Curilla, R. T. (2016). Vivências acadêmicas e sofrimento psíquico de estudantes de psicologia. Psicologia: Ciência e Profissão, 36(4), 831-846. https://doi. org/10.1590/1982-3703004142015

Araújo, M. F. M., Vasconcelos, H. C. A., Marinho, N. B.P., Freitas, R. W. J. F., \& Damasceno, M. M. C. (2016). Níveis plasmáticos de cortisol em universitários com má qualidade de sono. Cadernos Saúde Coletiva, 24(1), 105-110. https://doi. org/10.1590/1414-462X201600010227

Bardin, L. (2009). Análise de conteúdo. Edições 70.

Batistella, C. (2007). Abordagens contemporâneas do conceito de saúde. In A. F. Fonseca, \& A. D. Corbo (Orgs.). O território e o processo saúde-doença (pp. 51-86). EPSJV, Fiocruz.

Bonifácio, S. P., Silva, R. C. B., Montesano, F. T., \& Padovani, R. C. (2011). Investigação e manejo de eventos estressores entre estudantes de Psicologia. Revista Brasileira de Terapias Cognitivas, 7(1), 15-20. http://pepsic.bvsalud.org/scielo.php?script=sci arttext\&pid=S1808-56872011000100004 
Resolução n 510, de 7 de abril de 2016. (2016). Dispõe sobre as normas aplicáveis a pesquisas em Ciências Humanas e Sociais. https://www.in.gov.br/materia/-/asset_publisher/ Kujrw0TZC2Mb/content/id/22917581

Couto, D. A. C., Martin, D. R. S., Molina, G. E., Fontana, K. E., Junqueira Jr, L. F., \& Porto, L. G. G. (2019). Nível insuficiente de atividade física se associa a menor qualidade de vida e ao estudo noturno em universitários do Distrito Federal. Revista Brasileira de Ciências do Esporte, 41(3), 322-330. https://doi.org/10.1016/j.rbce.2018.04.017

Cristo, F., \& Günther, H. (2015). Hábito: por que devemos estudálo e o que podemos fazer? Psico, 46(2), 233-242. https:// doi.org/10.15448/1980-8623.2015.2.17816

Langame, A. P., Chehuen Neto J. A., Melo, L. N. B., Castelano, M. L., Cunha, M., \& Ferreira, R. E. (2016). Qualidade de vida do estudante universitário e o rendimento acadêmico. Revista Brasileira em Promoção da Saúde, 29(3), 313-325. https:// periodicos.unifor.br/RBPS/article/view/4796

Madeira, F. B., Filgueira, D. A., Bosi, M. L. M., \& Nogueira, J. A. D. (2018). Estilos de vida, habitus e promoção da saúde: algumas aproximações. Saúde e Sociedade, 27(1), 106-115. https://doi.org/10.1590/S0104-12902018170520

Mendonça, A. M. M. C., Gêda, T. F., Guimarães, J. E., Mendes, C. O., Manna, T. B. F., \& Monteiro, E. M. (2019). Perspectiva dos discentes de medicina de uma universidade pública sobre saúde e qualidade de vida. Revista Brasileira de Educação Médica, 43(1, Supl. 1), 228-235. https://doi. org/10.1590/1981-5271v43suplemento1-20190043

Moretti, F. A., \& Hübner, M. M. C. (2017). O estresse e a máquina de moer alunos do ensino superior: vamos repensar nossa política educacional? Revista Psicopedagogia, 34(105), 258-267. http://pepsic.bvsalud.org/scielo.php?script=sci arttext\&pid=S0103-84862017000300003\&lng=pt\&t|ng=pt

Oliveira, C. T., Carlotto, R., Carvalho, V., Silvio J. L., \& Dias, A. C. G. (2014). Adaptação acadêmica e coping em estudantes universitários brasileiros: uma revisão de literatura. Revista Brasileira de Orientação Profissional, 15(2), 177186. http://pepsic.bvsalud.org/scielo.php?script=sci arttext\&pid=S1679-33902014000200008\&lng=pt\&t|ng=pt
Oliveira, E. B., Zeitoune, R. C. G., Gallasch, C. H., Pérez Júnior, E. F., Silva, A. V., \& Souza, T. C. (2020). Transtornos mentais comuns em acadêmicos de enfermagem do ciclo profissionalizante. Revista Brasileira de Enfermagem, 73(1), e20180154. https://doi.org/10.1590/0034-7167-2018-0154

Padovani, R. C., Neufeld, C. B., Maltoni, J., Barbosa, L. N. F., Souza, W. F., Cavalcanti, H. A. F., \& Lameu, J. N. (2014). Vulnerabilidade e bem-estar psicológicos do estudante universitário. Revista Brasileira de Terapia Cognitiva, 10(1), 2-10. http://dx.doi.org/10.5935/1808-5687.20140002

Pereira, A., \& Cardoso, F. (2015). Ideação Suicida em Estudantes Universitários: Prevalência e Associação com a Escola e o Género. Paidéia, 25(62), 299-306. https://doi. org/10.1590/1982-43272562201503

Salvi, C. P. P., Mendes, S. S., \& Martino, M. M. F. (2020). Perfil dos estudantes que cursam enfermagem: qualidade de vida, sono e hábitos alimentares. Revista Brasileira de Enfermagem, 73(Supl. 1), e20190365. https://doi. org/10.1590/0034-7167-2019-0365

Selau, B., Damiani, M. F., \& Costas, F. A. T. (2017). Estudantes cegos na educação superior: o que fazer com os possíveis obstáculos? Acta Scientiarum Education, 39(4), 431-440. https://doi.org/10.4025/actascieduc.v39i4.28915

Silva, R. C., Pereira, A. A., \& Moura, E. P. (2020). Qualidade de vida e transtornos mentais menores dos estudantes de medicina do Centro Universitário de Caratinga (UNEC) Minas Gerais. Revista Brasileira de Educação Médica, 44(2), e064. https://doi.org/10.1590/1981-5271v44.2-20190179

Sousa, T. F., José, H. P. M., \& Barbosa, A. R. (2013). Condutas negativas à saúde em estudantes universitários brasileiros. Ciência \& Saúde Coletiva, 18(12), 3563-3575. https://doi.org/10.1590/S1413-81232013001200013

Tufik, S, Andersen, M. L., Pinto Jr, L. (2015). Sono e Sonhos. In R. Lent (Coord.). Neurociência da mente e do comportamento (pp. 271-285). Guanabara Koogan.

World Health Organization. (2014). Global status report on noncommunicable diseases 2014 [Relatório da situação global sobre doenças não transmissíveis 2014]. Who Library Cataloguing-In-Publication Data. https://apps.who. int/iris/bitstream/handle/10665/148114/9789241564854 eng.pdf?sequence $=1$ 